\title{
Quality Management: An Effective Approach to Success
}

\author{
Dhruba Kumar Budhathoki
}

\begin{abstract}
Product quality has entered the consciousness of organizations with a vengeance. It has become crystal clear that high-quality products have a distinct advantage in the market place, that market share can be gained or lost over the quality issue. Therefore, quality is a competitive priority. Quality is the only factor that ensures an organization's survival and growth. Quality focuses on meeting consumer need, meeting the competition, improving continuously and extending these concerns to all phases of business. Today, it has been well understood by managers that the real price of poor quality is lost consumers and ultimately, the death of an organization. Therefore to be successful in today's business environment, organizations must pay attention to quality. Hence, a systematic procedure has to be evolved and followed and different concepts of quality management have to be understood clearly for designing and executing the quality management programme effectively.
\end{abstract}

Keywords: Quality, quality management, approach, success.

\section{Introduction}

A producer is basically interested to see that the product is of acceptable quality to the customers, as it improves the competitive ability of the company and increases the sales, and no supplier can be in business if he fails to respond to the expectations of the customers, whether it is a part of the specifications or not. Since the quality of products has become an important aspect, the management should try to maintain the desirable quality at reasonable costs, for which they have to concentrate on a number of factors, such as the product design and specifications, the product process, the raw materials, machines and equipments, the expertise and skill of the persons who handle them and inspection of the final product. In nutshell, the management should maintain the quality of materials, quality of man power, quality of machines, quality of their activities etc.

The quality of men, machine, materials etc. depends upon the clear and comprehensive programme that must be capable of attempting some important tasks like:i)ordinating the activities of quality control and quality assurance ii) developing wide quality systems and procedures, iii) advising and helping in evolving quality programmes iv) auditing and implementing the quality system periodically. v) developing and organising the training and retraining programmes etc.

An effective programme for attaining the above tasks certainly reduce the cost of production by minimising the tangible and intangible losses due to poor quality, such as, materials scrapped or junked,labour and overheads in product scrapped, repairs on salvageable product, extra operations added because of the presence of defects, excess inspection costs, discount on seconds, charges on quality guarantee-free replacement, down grading of products, repair and processing of returned materials, delays and stoppages caused by defectives, customer goodwill etc. 
In other words, ineffective quality management increases the cost of failures, which may not only fall heavily on the manufacturer, hut also affect the but also affective the buyer, whose maintenance and operation cost may be substantial invites the attention on the understanding of quality management a model approach in quality management, measurement of different aspect for quality management etc. Since the understanding of the right concepts becomes imperative as it leads to right actions, an attempt has been done in this paper to discuss some of the important aspects of quality management with a view to improve the awareness about quality management among the different sections and to draw their attention towards the improvement of the theoretical bases of quality management and their applicability.

\subsection{Quality Management Issues}

Today many companies are realising mainly three problems,i) the sharp increase in customers' quality requirements, ii) becoming, present quality practices and techniques as out-moded, due to increased demand for higher quality products,iii) an increase in quality costs at higher rate. These problems pose two main challenges to the management as :i) considerable improvement in thequality of products and quality practices, ii) substantial reduction in the overall costs of maintaining quality.

The above challenges and problems demand an effective quality management. Where, the quality management is an effective system for integrating the quality development, quality maintenance and quality improvement efforts of the various groups in an organisation. So as to enable marketing engineering, production and service at the most economical levels which allow for all customer satisfaction. In simple words, quality management is that which guides the coordinated actions of people, machines and information to achieve the goals. The quality management has a very wide coverage 1 as it deals with many aspects at different stages. Some of them are as follows:

- Marketing: evaluates the level of quality, which customers want and for which they may be willing to pay.

- Engineering : reduces the marketing evaluation to exact specification.

- Purchasing chooses contracts with, and retains vendors for parts and materials.

- Manufacturing Engineering: selects the jobs, tools and process for production.

- Manufacturing Supervision and Shop Operators : exert a major quality influence during parts making, subassembly and final assembly.

- Mechanical Inspection and Functional Test : check conformance to specifications.

- Shipping : influences of packaging and transportation.

- Installation and Product Service : ensure proper operation by installing the product according to proper instructions and maintaining It through service.

\section{Model Approach}

The quality management starts with the identification of customer quality requirement and end with only when the product has been placed in the hands of a customer who remains 88 
satisfied. Specifically, a model approach in an effective quality management includes.

- 'Identification of customer requirements and designing of product' to fully meet such customer requirements including performance, safety, life characteristics and aesthetics, with due considerations to ease and economy of manufacture.

- 'Adherence to specifications', with emphasis on defect prevent ion in all areas of operations.

- 'Continuous improvement' in products/ processes/ systems through competitive technological base.

- 'Use of scientific system' for vendor selection, development, evaluation, surveillance and providing assistance to the vendors, in materials, management activity.'

- 'Planned and systematic programmes' for acquainting customer adequately for the proper usage of products/systems.

- 'Involvement of personnel' from all functions at all levels for development and maintenance of quality systems.

\section{Measurement}

The measurements of quality, costs, customer satisfaction, systems conformance etc. arc the most important aspects, since they provide bases for the effective quality management and also essential for the organisational success. Thus, the following some important aspects, which have to be measured carefully and systematically for the effective evaluat ion of quality, management.

Quality : Timely_measurement and reporling of quality l\&el data are very much useful for ass essing quality performance, sett ing quality-level goals and evaluating corrective actions or eff orts. Such information becomes the basis for establishing and imp roving goals, priority schedules etc.

Costs :The periodic collect ion and analysis of quality costs monitor the cost effectiveness of the quality system, which is fundamental to achieve the goal of full customer quality satisfaction at reasonable quality costs.

Customer satisfaction :The useful predictor of customer satisfaction is the intensive examination ofsmall samples of finished product. The result of this type of customercentered quality audit, together with other measurements after the product is in use, evaluate the effectiveness 01 the quality system from the view point of the customer and alert the management for taking rapid product corrective action. They provide valuable input towards the development of new models and similar products.

System conformance :The assessment of the quality-system procedures, identi1ring the deviations from such system, provide some data which is helpful to management to determine the adequate quality plans, quality responsibilities and procedures. This in turn, pinpoints the areas where improvements are necessary. 


\section{Conclusions and Recommedations}

In this competitive era, a businessman has to keep continuous watch over the quality of goods and services, as it earns goodwill and increases the sales. Particularly, in a country like Nepal, the use of the quality management has an important place not only in the context of wide variations encountered in raw materials and in machines, but also of the need of earning foreign exchange.

The quality of men, machine, materials etc. have direct bearing on the product quality, for which the management is in need of clear and comprehensive quality management programme. An effective quality management certainly reduces the cost of production by minimising losses due to poor quality or, In other words, the cost of failure will be controlled. This enables the organisation to supply quality goods at reasonable price.

Hence, a systematic procedure has to be evolved and followed, and different concepts of quality management have to be understood clearly for designing and executing the quality management programme effectively. The academicians, engineers and others have to contribute their knowledge for the development of concepts of quality management in order to simplify the quality management and to make it more popular. So as to encourage the entrepreneurs to adopt the quality management programme with ease.

\section{BIBLIOGRAPHY}

Armand, V. F. (1986). Total quality control (3rd ed.). New Delhi: McGraw Hill book Co.

Adam, E. F., Hershauer, J. C., \& Ruch, W. A. (1978). Measuring the quality dimonsionservice productivity. National Science Foundation No. APR 76-07140. University of Missentri-Arizona State University.

Duncan, A. J. (1974). Quality control and industrial statistics (4th ed.). Homewood: Irwin.

Pant P. R. (2003). Principles of management. Kathmandu: Buddha Academic Enterprises Pvt. Ltd.

Smith, C. S. (1969). Quality and reliability: An integrated approach. New York: Pitman. 